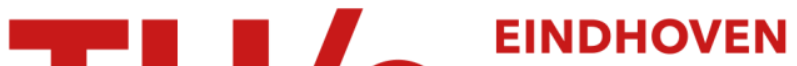 UNIVERSITY OF TECHNOLOGY
}

\section{Three-Dimensional Analytical calculation of the torque between permanent magnets in magnetic bearings}

Citation for published version (APA):

Janssen, J. L. G., Paulides, J. J. H., Compter, J. C., \& Lomonova, E. (2010). Three-Dimensional Analytical calculation of the torque between permanent magnets in magnetic bearings. IEEE Transactions on Magnetics, 46(6), 1748-1751. https://doi.org/10.1109/TMAG.2010.2043224

DOI:

10.1109/TMAG.2010.2043224

Document status and date:

Published: 01/01/2010

\section{Document Version:}

Publisher's PDF, also known as Version of Record (includes final page, issue and volume numbers)

\section{Please check the document version of this publication:}

- A submitted manuscript is the version of the article upon submission and before peer-review. There can be important differences between the submitted version and the official published version of record. People interested in the research are advised to contact the author for the final version of the publication, or visit the $\mathrm{DOI}$ to the publisher's website.

- The final author version and the galley proof are versions of the publication after peer review.

- The final published version features the final layout of the paper including the volume, issue and page numbers.

Link to publication

\section{General rights}

Copyright and moral rights for the publications made accessible in the public portal are retained by the authors and/or other copyright owners and it is a condition of accessing publications that users recognise and abide by the legal requirements associated with these rights.

- Users may download and print one copy of any publication from the public portal for the purpose of private study or research.

- You may not further distribute the material or use it for any profit-making activity or commercial gain

- You may freely distribute the URL identifying the publication in the public portal.

If the publication is distributed under the terms of Article 25fa of the Dutch Copyright Act, indicated by the "Taverne" license above, please follow below link for the End User Agreement:

www.tue.nl/taverne

Take down policy

If you believe that this document breaches copyright please contact us at:

openaccess@tue.nl

providing details and we will investigate your claim. 


\title{
Three-Dimensional Analytical Calculation of the Torque Between Permanent Magnets in Magnetic Bearings
}

\author{
Jeroen L. G. Janssen, Johannes J. H. Paulides, John C. Compter, and Elena A. Lomonova \\ Department of Electrical Engineering, Group of Electromechanics and Power Electronics, Eindhoven University of Technology, \\ $5600 \mathrm{MB}$, The Netherlands
}

\begin{abstract}
In the high-precision industry, accurate vibration isolation and magnetic levitation are extremely important. As a result, high-performance vibration isolation and magnetic bearings based on permanent magnets are increasingly considered. This paper proposes improved analytical expressions for the torque on cuboidal permanent magnets applied to a magnetic bearing. These novel expressions are valid for any relative magnet position, especially when surfaces of the different magnets are in the same plane. Further, the torque can be obtained with respect to any reference point. Although these equations seem rather complicated, they enable an extremely fast and accurate calculation of the torque on a permanent magnet in the presence of a magnetic field of another permanent magnet. These properties enable a fast design and optimization process of such bearings using fully analytical expressions.
\end{abstract}

Index Terms-Magnetic levitation, modeling, permanent magnet, torque, vibrations.

\section{INTRODUCTION}

D UE to the demand for ever higher performance of advanced vibration isolation systems, engineers increasingly implement solutions that were considered too risky in the past. The vibration isolation systems in high-precision applications (Fig. 1(a), (b)) should simultaneously exhibit high force density and low stiffness with vacuum compatibility. These systems are nowadays often air-based since PM-based systems are considered unsuitable for such high-precision applications, although vibration isolators and magnetic bearings based on permanent magnets (PMs) are increasingly considered.

$\mathrm{PM}$ bearings, such as shown in the schematic example in Fig. 2, have distinct features such as clean, noiseless, and vibration and maintenance free, although high costs due to control apparatus prevent their wide applications at present [1]. However, due to their inherently high control bandwidth and accuracy they are under focus for high-performance bearing applications [2]-[5]. Accurate modeling tools are essential to obtain designs suitable to facilitate the ever growing demands.

The interaction force, stiffness and torque matrices are important design and control parameters for PM bearings and suspensions. Due to the contactless magnetic bearing topology not only the translational but also the rotational degrees of freedom of the PM-based device are passively unstable [6] and therefore require active stabilization. Although numerical means are often considered very interesting for evaluating the mechanical properties of the magnetic bearing, analytical expressions are a more elegant way due to their limited computational cost. Analytical surface charge modeling was used in [7]-[10] to obtain the interaction force between PMs with parallel or perpendicular magnetization directions. Analytical expressions for the torque on the PMs are proposed in [11] using the Virtual Work method, however these are limited to torque around the center point of the respective magnet.

Manuscript received October 30, 2009; accepted January 31, 2010. Current version published May 19, 2010. Corresponding author: J. L. G. Janssen (e-mail: j.1.g.janssen@tue.nl).

Color versions of one or more of the figures in this paper are available online at http://ieeexplore.ieee.org.

Digital Object Identifier 10.1109/TMAG.2010.2043224

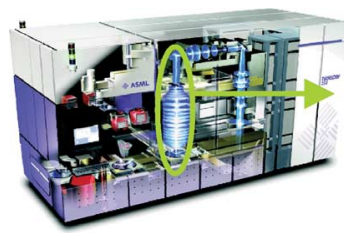

(a)

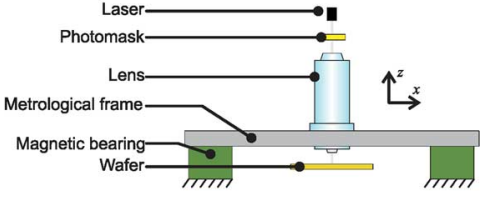

(b)
Fig. 1. Impression of (a) a high-precision lithographic machine (Courtesy of ASML, Veldhoven, The Netherlands) and (b) the static magnetic bearing within the machine.

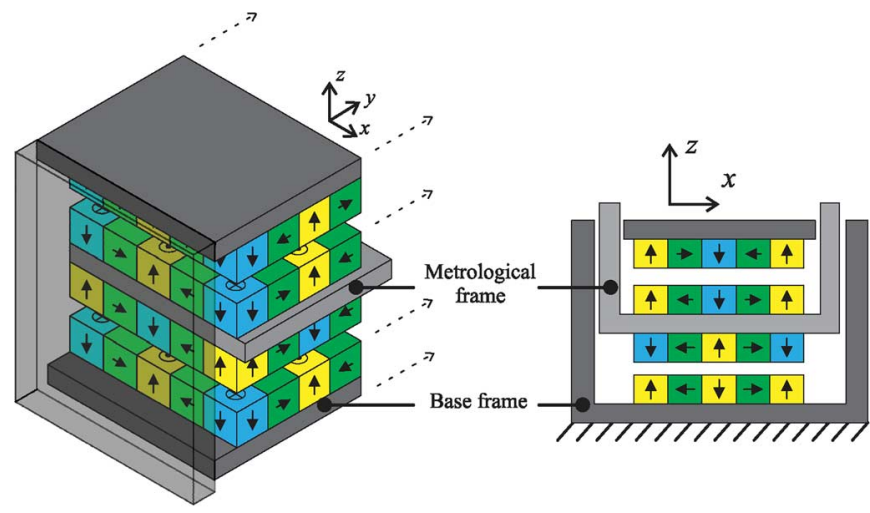

(a)

(b)

Fig. 2. (a) 3-D impression and (b) cross section of the high-precision magnetic bearing magnet topology to compensate the gravity.

In this paper, the torque expressions are expanded towards such a form that torque can directly be obtained around any given point in space instead of around the center of the PM. The expressions presented are derived using the Lorentz force method. Further, discontinuous points which occur within these analytical solutions are discussed and identified. Additional analytical expressions which ensure the continuity of the obtained torque expressions are then proposed. A comparison with seminumerical and numerical models, and with measurement results validates the analytical calculation of the torque on the PMs. With these expressions it is possible to optimize planar bearing structures using fully analytical expressions [12]. 


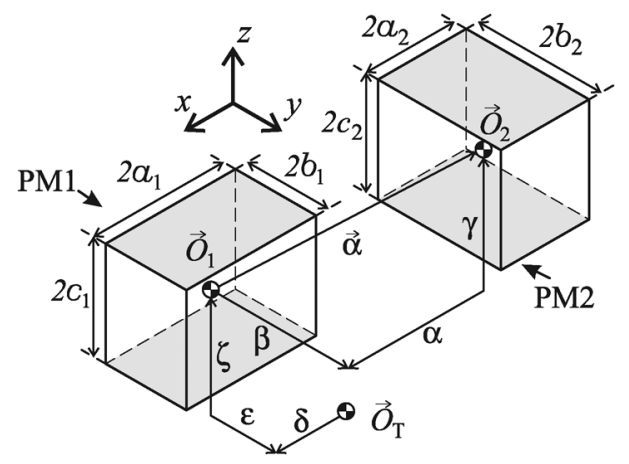

Fig. 3. Definition of the variables used in the torque expressions. Both magnets are magnetized along the $z$-axis.

In Section II the variables which define the model are described and they are used in Section III to obtain analytical torque expressions. The discontinuities which occur in such a model are discussed and solved in Section IV. Section V compares the results with other models and finally the conclusions are presented in Section VI.

\section{MODEL DESCRIPTION}

In this paper, two cuboidal permanent magnets, PM1 and PM2, are studied in the cartesian coordinate system as is shown in Fig. 3. It is assumed that these PMs are parallel to each other and that the respective magnetization vectors $\vec{M}_{1}$ and $\vec{M}_{2}$ are homogeneous and constant. The dimensions of the PM are defined by $2 a_{1}, 2 b_{1}, 2 c_{1}$ and $2 a_{2}, 2 b_{2}, 2 c_{2}$, respectively. The center of PM1, $\vec{O}_{1}$, is located at $[0,0,0]^{T}$ and that of PM2, $\vec{O}_{2}$, at $[\alpha, \beta, \gamma]^{T}$ represented by the vector $\vec{\alpha}$. The reference point for the torque calculation, $\vec{O}_{T}$, is located at $[\delta, \epsilon, \zeta]^{T}$. In the charge model [13] each PM is replaced by an equivalent magnetic charge density, $\sigma_{m}$, given by

$$
\sigma_{m}(\vec{x})=\vec{M}_{m} \cdot \vec{n}(\vec{x})=\mu_{0}^{-1} \vec{B}_{r} \cdot \vec{n}(\vec{x})
$$

where $\vec{n}$ is the normal vector of the PM surfaces, $\vec{B}_{r}$ is its remanent flux density and $\mu_{0}$ is the permeability of vacuum. The vector $\vec{x}$ is the observation point, given by $[x, y, z]^{T}$. In this paper the torque on PM2 is derived for the case that both PMs are magnetized along the $z$-axis. For other parallel magnetization directions a rotation of the coordinate system suffices to obtain the torque. The torque on PM1 can be derived similarly, but is equal and opposite to the torque on PM2. The derivation for the torque for perpendicular magnetized PMs is performed using the same method as described below and is not further elaborated on in this paper.

\section{Analytical Torque Calculation}

This paper utilizes the Lorentz force method [14] to obtain the analytical torque expressions as opposed to the virtual work method used for torque calculations in [11]. Furthermore this paper proposes expressions for torque calculation around any reference point instead of solely around the magnet center coordinates. The torque calculation is based on the same expressions as the force calculation and is here obtained for PM2 with position vector $[\alpha, \beta, \gamma]^{T}$ represented by $\vec{\alpha}$. A similar approach provides the torque on PM1 and is left for the reader. The expression to obtain the Lorentz force on PM2 has the form [10]

$$
\begin{aligned}
\vec{F}(\vec{\alpha}) & =\iint_{S} \vec{f}(\vec{x}) \mathrm{d} S \\
\vec{f}(\vec{x}) & =\sigma_{m}(\vec{x}) \vec{B}(\vec{x}) .
\end{aligned}
$$

The variable $S$ is the surface of the PM2 and $\vec{f}(\vec{x})$ is a virtual force distribution over this surface. The external magnetic flux density which is induced by PM1, $\vec{B}$, is analytically described in [7].

To obtain correct analytical expressions for the torque on one of the PMs it necessary to integrate the torque distribution over the magnet surface. This gives

$$
\begin{aligned}
\vec{T}(\vec{\alpha}) & =\iint_{S} \vec{t}(\vec{x}) \mathrm{d} S \\
\vec{t}(\vec{x}) & =\vec{r}(\vec{x}) \times \vec{f}(\vec{x}) .
\end{aligned}
$$

The arm $\vec{r}(\vec{x})$ is given by $\vec{x}-\vec{O}_{T}$ and (4) becomes

$$
\vec{T}(\vec{\alpha})=\iint_{S}\left(\begin{array}{l}
\sigma_{m}(\vec{x})\left(r_{y} B_{z}(\vec{x})-r_{z} B_{y}(\vec{x})\right) \\
\sigma_{m}(\vec{x})\left(r_{z} B_{x}(\vec{x})-r_{x} B_{z}(\vec{x})\right) \\
\sigma_{m}(\vec{x})\left(r_{x} B_{y}(\vec{x})-r_{y} B_{x}(\vec{x})\right)
\end{array}\right) \mathrm{d} S .
$$

After symbolically solving (6) the resulting torque expressions for PM2 obtain the form

$$
\vec{T}(\vec{\alpha})=\frac{B_{r_{1}}^{z} B_{r_{2}}^{z}}{4 \pi \mu_{0}} \sum_{i=0}^{1} \sum_{j=0}^{1} \sum_{k=0}^{1} \sum_{l=0}^{1} \sum_{m=0}^{1} \sum_{n=0}^{1}(-1)^{i+j+k+l+m+n} \vec{\xi}
$$

In this equation $B_{r_{1}}^{z}$ and $B_{r_{2}}^{z}$ are the remanent flux density components along the $z$ axis of the respective PMs. The vector $\vec{\xi}$ contains the integrand and is separated in three cartesian components $\xi_{x}, \xi_{y}$ and $\xi_{z}$. These integrands are given in

$$
\begin{aligned}
& \xi_{x}= \frac{1}{8}\left(-2 C_{w}\left(-4 v u+s^{2}+2 v s\right)-w\left(-8 v u+s^{2}+8 C_{v} s+6 v s\right)\right. \\
&+4\left(2 C_{v} u w \operatorname{coth}^{-1}\left(\frac{u}{s}\right)+w\left(v^{2}+2 C_{v} v-w\left(2 C_{w}+w\right)\right) \operatorname{coth}^{-1}\left(\frac{v}{s}\right)\right. \\
& \quad-u\left(2 w\left(C_{w}+w\right) \tan ^{-1}\left(\frac{v}{w}\right)+2 v\left(C_{w}+w\right) \log (s-u)\right. \\
&\left.\left.\quad+\left(w^{2}+2 C_{w} w-v\left(2 C_{v}+v\right)\right) \tan ^{-1}\left(\frac{u v}{w s}\right)\right)\right) \\
&\left.\quad+2\left(2 C_{w}+w\right)\left(u^{2}+w^{2}\right) \log (v+s)\right) \\
& \xi_{y}=\frac{1}{8}\left(\left(2 C_{w}+w\right) u^{2}-8 u v\left(C_{w}+w\right)+8 u v\left(C_{w}+w\right) \log (s-v)\right. \\
&+4 C_{w} u s+6 w s u+\left(2 C_{w}+w\right)\left(v^{2}+w^{2}\right) \\
&+4 w\left(w^{2}+2 C_{w} w-u\left(2 C_{u}+u\right)\right) \operatorname{coth}^{-1}\left(\frac{u}{s}\right) \\
&+4 v\left(-2 C_{u} w \operatorname{coth}^{-1}\left(\frac{v}{s}\right)+2 w\left(C_{w}+w\right) \tan ^{-1}\left(\frac{u}{w}\right)\right. \\
&+\left.\left(w^{2}+2 C_{w} w-u\left(2 C_{u}+u\right)\right) \tan ^{-1}\left(\frac{u v}{w s}\right)\right) \\
&\left.-2\left(2 C_{w}+w\right)\left(v^{2}+w^{2}\right) \log (u+s)+8 C_{u} w s\right)
\end{aligned}
$$




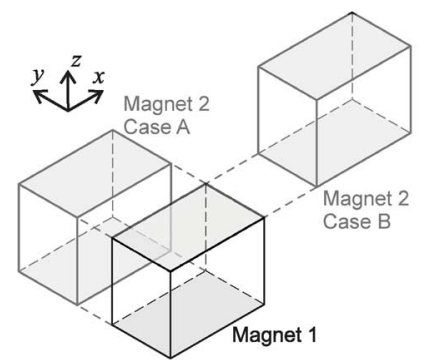

(a)

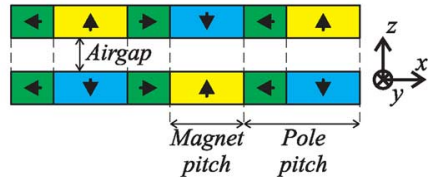

(b)
Fig. 4. (a) Two cases of alignment of the PM surfaces and (b) cross section of permanent magnets in a magnetic bearing with a planar Halbach array.

$$
\begin{aligned}
\xi_{z}=\frac{1}{36} & \left(-u^{3}-18 v u^{2}-6 u\left(w^{2}+6 C_{u} v-3 v\left(2 C_{v}+v\right)+3 C_{v} s\right)\right. \\
+ & v\left(v^{2}+6\left(w^{2}+3 C_{u} s\right)\right)+6 w\left(w^{2}-3 v\left(2 C_{v}+v\right)\right) \tan ^{-1}\left(\frac{u}{w}\right) \\
& -6 w\left(w^{2}-3 u\left(2 C_{u}+u\right)\right) \tan ^{-1}\left(\frac{v}{w}\right) \\
& -9\left(2\left(v^{2}+2 C_{v} v-u\left(2 C_{u}+u\right)\right) w \tan ^{-1}\left(\frac{u v}{w s}\right)\right. \\
& -2 u\left(2 C_{u}+u\right) v \log (s-u)-\left(2 C_{v}+v\right)\left(v^{2}-w^{2}\right) \log (u+s) \\
& \left.\left.+2 u v\left(2 C_{v}+v\right) \log (s-v)+\left(2 C_{u}+u\right)\left(u^{2}-w^{2}\right) \log (v+s)\right)\right)
\end{aligned}
$$

and are substituted in (7). Variables $\vec{C}, u, v, w$, and $s$ are defined by

$$
\begin{aligned}
\vec{C} & =\left(\begin{array}{c}
C_{u} \\
C_{v} \\
C_{w}
\end{array}\right)=\left(\begin{array}{c}
(-1)^{i} a_{1}-\delta \\
(-1)^{k} b_{1}-\epsilon \\
(-1)^{m} c_{1}-\zeta
\end{array}\right) \\
u & =\alpha-(-1)^{i} a_{1}+(-1)^{j} a_{2} \\
v & =\beta-(-1)^{k} b_{1}+(-1)^{l} b_{2} \\
w & =\gamma-(-1)^{m} c_{1}+(-1)^{n} c_{2} \\
s & =\sqrt{u^{2}+v^{2}+w^{2}}
\end{aligned}
$$

with the variables defined in Fig. 3. Although these equations seem rather complicated, they enable an extremely fast and accurate calculation of the torque on a PM in the presence of a magnetic field of another PM.

\section{DiscontinUITIES IN THE ANALYTICAL EXPRESSIONS}

From (12)-(15) it is observed that for certain combinations of $i \ldots n, a_{1} \ldots c_{2}$ and $\alpha \ldots \gamma$ the variables $u, v$ or $w$ become zero. This occurs if the edges of two PMs are on the same line. Two of the cases where this happens are shown in Fig. 4(a). Specifically, using (12)-(15) it can be derived for case $A$ in Fig. 4(a) that

$$
\begin{array}{r}
\left.u\right|_{i=j, a_{1}=a_{2}, \alpha=0}=0 \\
\left.w\right|_{m=n, c_{1}=c_{2}, \gamma=0}=0
\end{array}
$$

In such case the expressions (8)-(10) and as a result the torque become undefined in that specific position. Similarly it can be derived for case $B$ that $v=w=0$. Fig. 4(b) demonstrates that in a magnetic bearing with e.g., Halbach arrays such alignment is a common issue (dashed lines), which would result in undefined torque results.
Although linear interpolation around those non-solving points is not difficult to implement, it is a slower and less accurate method compared to the direct analytical calculation. Accuracy of the linear interpolation can be increased by taking more sample points, however at the cost of increased computational efforts. A fully analytical and computationally inexpensive solution is therefore considered to be more suitable. In [15] such analytical continuous solution was given for the interaction force and stiffness expressions. A similar approach is used in this paper to obtain the novel fully analytical torque expressions.

In the cases that $u=v=0, u=w=0$, or $v=w=0$, the analytical expressions for $\vec{\xi}$ are obtained by taking its respective limit points. This results in equations which are suitable for those particular positions, given by

$$
\begin{aligned}
& \lim _{\substack{u \rightarrow 0 \\
v \rightarrow 0}} \vec{\xi}_{x}=\frac{1}{8} w\left(-w^{2}-2 C_{w} w-8 C_{v} \sqrt{w^{2}}\right. \\
& \left.+2 w\left(2 C_{w}+w\right) \log \left(-\sqrt{w^{2}}\right)\right) \\
& \lim _{\substack{u \rightarrow 0 \\
v \rightarrow 0}} \vec{\xi}_{y}=\frac{1}{8} w\left(w^{2}+2 C_{w} w+8 C_{u} \sqrt{w^{2}}\right. \\
& \left.-2 w\left(2 C_{w}+w\right) \log \left(-\sqrt{w^{2}}\right)\right) \\
& \lim _{\substack{u \rightarrow 0 \\
v \rightarrow 0}} \vec{\xi}_{z}=\frac{1}{4}\left(C_{u}-C_{v}\right) w^{2} \log \left(w^{2}\right) \\
& \lim _{\substack{u \rightarrow 0 \\
w \rightarrow 0}} \vec{\xi}_{x}=-\frac{1}{4} C_{w} v\left(v+2 \sqrt{v^{2}}\right) \\
& \lim _{\substack{u \rightarrow 0 \\
w \rightarrow 0}} \vec{\xi}_{y}=-\frac{1}{4} C_{w} v^{2}\left(\log \left(v^{2}\right)-1\right) \\
& \lim _{\substack{u \rightarrow 0 \\
w \rightarrow 0}} \vec{\xi}_{z}=\frac{1}{72} v\left(2\left(v^{2}+18 C_{u} \sqrt{v^{2}}\right)\right. \\
& \left.+9 v\left(2 C_{v}+v\right) \log \left(v^{2}\right)\right) \\
& \lim _{\substack{v \rightarrow 0 \\
w \rightarrow 0}} \vec{\xi}_{x}=\frac{1}{4} C_{w} u^{2}\left(\log \left(u^{2}\right)-1\right) \\
& \lim _{\substack{v \rightarrow 0 \\
w \rightarrow 0}} \vec{\xi}_{y}=\frac{1}{4} C_{w} u\left(u+2 \sqrt{u^{2}}\right) \\
& \lim _{\substack{v \rightarrow 0 \\
w \rightarrow 0}} \vec{\xi}_{z}=-\frac{1}{72} u\left(2\left(u^{2}+18 C_{v} \sqrt{u^{2}}\right)\right. \\
& \left.+9 u\left(2 C_{u}+u\right) \log \left(u^{2}\right)\right) .
\end{aligned}
$$

It is observed that the logarithmic terms in (18) and (19) cause complex results. Due to the symmetric summations in (7) these imaginary terms are canceled, hence, the obtained torque only consists of real numbers. By applying these equations in the appropriate cases that are mentioned a fully analytical and continuous torque calculation method for cuboidal PMs is obtained. In combination with the analytical continuous force and stiffness equations from [15] this results in a versatile analytical tool for the analysis, design and optimization of PM bearings with cuboidal magnets.

\section{VALIDATION}

The torques obtained by the expressions derived in this paper are compared with torque results which are obtained by the numerical Maxwell Stress integration on the analytical field (mesh 
TABLE I

Dimensions of the MeAsured MAGnets, DeFined In Fig. 3

\begin{tabular}{|c|c|c|c|c|c|}
\hline $2 a_{1}$ & $10 \mathrm{~mm}$ & $2 a_{2}$ & $10 \mathrm{~mm}$ & $\alpha$ & $0 \mathrm{~mm}$ \\
\hline $2 b_{1}$ & $26 \mathrm{~mm}$ & $2 b_{2}$ & $26 \mathrm{~mm}$ & $\beta$ & $-8 \mathrm{~mm}$ \\
\hline $2 c_{1}$ & $14 \mathrm{~mm}$ & $2 c_{2}$ & $14 \mathrm{~mm}$ & $\gamma$ & $15 \mathrm{~mm}$ \\
\hline$\vec{M}_{1}$ & $M \vec{e}_{z}$ & $\vec{M}_{2}$ & $-M \vec{e}_{z}$ & $B_{r 1}=B_{r 2}$ & $1.23 \mathrm{~T}$ \\
\hline
\end{tabular}

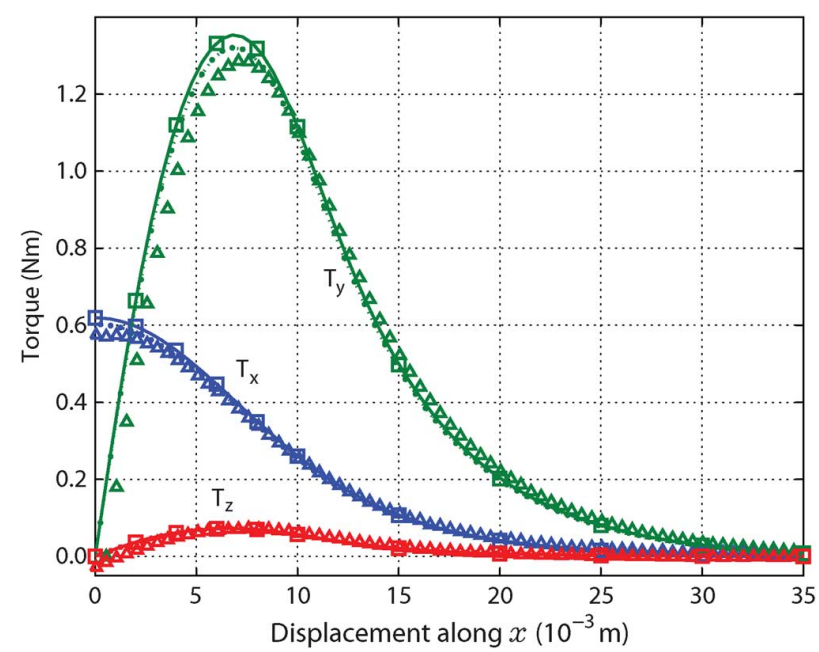

Fig. 5. Torque results of the FEM model ( $\square$ ), Maxwell Stress results ( $\ldots)$, the analytical charge model proposed in this paper $(-)$ and measurements $(\triangle)$.

of $0.2 \mathrm{~mm}$ ), finite element method (FEM) [16] results and measurements. This is performed for two magnets with the dimensions shown in Table I, with the reference point for the torque at $[0,0,-47]^{T} \mathrm{~mm}$. Fig. 5 shows the high correspondence between all methods, hence, verifies the fast-solving torque calculation proposed in this paper.

\section{CONCLUSION}

This paper presents novel analytical torque expressions for cuboidal permanent magnets. These expression enable the direct calculation of the torque on the permanent magnets with respect to any torque reference point, hence, are not restricted to computations around the center point of the object. Further, the special cases in which they are undefined are researched and expressions for the non-solving terms are proposed. The analyt- ical solution is verified with numerical (FEM) and semi-numerical models (Maxwell Stress), and with measurements, which illustrates the accuracy of these fast-solving analytical expressions. Although they seem rather complex, the obtained expressions solve extremely fast. This makes them very suitable for the design and optimization of permanent magnet devices such as planar static magnetic bearings and vibration isolators.

\section{REFERENCES}

[1] A. T. A. Peijnenburg, J. P. M. Vermeulen, and J. van Eijk, "Magnetic levitation systems compared to conventional bearing systems," Microelectron. Eng., vol. 83, no. 4-9, pp. 1372-1375, 2006.

[2] J. L. G. Janssen, J. J. H. Paulides, and E. A. Lomonova, "Passive magnetic suspension limitations for gravity compensation," J. Syst. Des. Dynam., vol. 3, no. 4, pp. 671-680, 2009.

[3] J. W. Jansen, C. M. M. van Lierop, E. A. Lomonova, and A. J. A. Vandenput, "Ironless magnetically levitated planar actuator," J. Appl. Phys., vol. 103, no. 7, pp. 07E905-1-07E905-3, 2008.

[4] J. M. M. Rovers, J. W. Jansen, E. A. Lomonova, and M. J. C. Ronde, "Calculation of the static forces among the permanent magnets in a halbach array," IEEE Trans. Magn., vol. 45, no. 10, pp. 4372-4375, Oct. 2009.

[5] W. Robertson, B. Cazzolato, and A. Zander, "A multipole array magnetic spring," IEEE Trans. Magn., vol. 41, no. 10, pp. 3826-3828, Oct. 2005.

[6] S. Earnshaw, "On the nature of the molecular forces which regulate the constitution of the luminuferous ether," Trans. Cambridge Phil. Soc., vol. VII:1, pp. 97-112, 1839.

[7] G. Akound and J. P. Yonnet, "3D analytical calculation of the forces exerted between two cuboidal magnets," IEEE Trans. Magn., vol. 20, no. 5, pp. 1962-1964, Sep. 1984.

[8] F. Bancel, "Magnetic nodes," J. Appl. Phys., vol. 32, pp. 2155-2161, Jun. 1999.

[9] H. Allag and J. P. Yonnet, "3D analytical calculation of interactions between perpendicularly magnetized magnets application to any magnetization direction," Sensor Lett., vol. 7, no. 3, pp. 486-491, Aug. 2009.

[10] J. L. G. Janssen, J. J. H. Paulides, and E. Lomonova, "Analytical calculation of interaction force between orthogonally magnetized permanent magnets," Sensor Lett., vol. 7, no. 3, pp. 442-445, Aug. 2009.

[11] H. Allag and J.-P. Yonnet, "3-D analytical calculation of the torque and force exerted between two cuboidal magnets," IEEE Trans. Magn., vol. 45, no. 10, pp. 3969-3972, Oct. 2009.

[12] L. Encica, J. J. H. Paulides, and E. Lomonova, "Space-mapping optimization in electromechanics: An overview of algorithms and applications," COMPEL, vol. 28, no. 5, pp. 1216-1226, 2009.

[13] E. P. Furlani, Permanent Magnet and Electromechanical Devices: Materials, Analysis and Applications, 6th ed. London, U.K.: Academic, 2001.

[14] E. P. Furlani, "Formulas for the force and torque of axial couplings," IEEE Trans. Magn., vol. 29, no. 5, pp. 2295-2301, Sep. 1993.

[15] J. L. G. Janssen, J. J. H. Paulides, and E. Lomonova, "Analytical force and stiffness calculations for magnetic bearings and vibration isolation," in Int. Symp. Magnetic Fields (ISEF), Arras, France, Sep. 2009.

[16] “Flux 10 User's Guide," Cedrat Corp., Grenoble, France, 2007, release 10.2.1. 